\title{
When Home Hospice Patients Discharge to Nursing Home: A Mixed Method
}

\author{
Soohyoung Rain Lee \\ Aging and Welfare Lab, Los Angeles, USA \\ Email: rainl@agingandwelfarelab.com
}

How to cite this paper: Lee, S.R. (2021) When Home Hospice Patients Discharge to Nursing Home: A Mixed Method. Open Journal of Nursing, 11, 442-454. https://doi.org/10.4236/ojn.2021.116038

Received: April 28, 2021

Accepted: June 14, 2021

Published: June 17, 2021

Copyright $\odot 2021$ by author(s) and Scientific Research Publishing Inc. This work is licensed under the Creative Commons Attribution International License (CC BY 4.0).

http://creativecommons.org/licenses/by/4.0/

(c) (i) Open Access

\begin{abstract}
Background: Hospice care is to provide necessary medical care and support for patients and the families at the end of life (EOL). Hospice care patients typically withdraw from aggressive treatment. Even though home hospice has been shown to improve the quality of care, home hospice patients still revoke the services for various reasons. A little is known about where home hospice patients are being transferred. This study aims to address this gap and explore common reasons for home hospice discharge and placements, where patients being transferred other than home. Methods: Data were retrieved from the 2007 National Home and Hospice Care Survey (NHHCS). NHHCS is one in a series of nationally representative sample surveys of U.S. home health and hospice agencies. Results: Within identified home hospice patients, approximately $82.1 \%$ were deceased at discharge, and 846 (18.2\%) were discharged for other reasons, including patients being stabilized or improved (30.2\%), aggressive treatment (31.8\%), moved (e.g., geographically, 13.5\%) and others. Patients lived with a spouse were less likely to utilize external resources, like volunteers, thereby more likely to discharge patients to long-term facilities. Discussion: The current study suggest that it is difficult for the family to give all remaining care for their loved ones despite the support and resources for those home hospice patients. The characteristics of those who transferred to nursing facilities from home hospice will be discussed throughout.
\end{abstract}

\section{Keywords}

Live Discharge, Nursing Facilities, Home Hospice

\section{Introduction}

Hospice care is to provide necessary medical care and support for patients and the families at the end of life (EOL). Hospice care patients typically withdraw aggressive treatment, including hospitalization [1]. The majority of hospice pa- 
tients receive care at home [2] [3] and has been shown to improve quality of care and satisfaction for both patients and caregivers (e.g., family members) [4] [5].

In response to the increasing number of hospice patients and admission, the U.S. Medicare hospice benefit has expanded. Patients can now receive hospice care at long-term care facilities, including skilled nursing facilities and assisted living [6] [7]. Typically, hospice patients receive care in their own residency, and this reflects the common preferences of dying place, home [8] [9].

Despite the individuals' preference for dying at home, the number of live discharges increases [10] [11]. Approximately 6 percent of home hospice patients revoked the care and admitted to the hospital within 30 days of discharge [10] [12] and likely to die within six months without being re-enrolled in hospice care [13]. This is problematic as the transitioning experience may cause stress and burdensome for families and patients due to unwanted aggressive treatment during the end of life and unsatisfactory symptom management [14] [15].

\section{Home Hospice Patient: What We Know}

While majority of home hospice patients discharge at deceased, though those of who discharged other than being deceased, including stabilized condition, to receive aggressive treatment related to primary diagnosis, and eligibilities that are related to the length of stays [16] [17]. Further, low-income families were likely to transfer to nursing facilities due to limited resources, such as financial limitations to hire additional caregivers [18] [19]. Importantly, the inadaptable transitioning of home hospice to nursing facilities tends to increase over time [20]. Although there is limited information on transitioning home hospice to other long-term care facilities, previous studies have suggested transferring to a nursing home may decrease patients' and families' satisfaction [21] [22].

Terminally ill patients to choose hospice setting to receive comfort care during at the end of stage of their lives, ultimately, to achieve quality of death at home [23] [24]. However, increasing number of home hospice patients being discharged to nursing facilities, which in fact decrease both patients and family members' satisfaction. It is important to understand the reasons for patients to being discharged to nursing facility to provide improved care for those home hospice care patients.

The current study attempted to revisit home hospice characteristics live discharge and explore the possible association between individual patients and families to decide live discharge and placements. This observational-exploratory study has two objectives:

Objective 1: Demographics of live discharge patients and what extend impact live discharge decisions and hospice settings other than home.

Objective 2: The reasons for discharge other than deceased.

Meeting these objectives will help researchers and hospice social workers understand the core cause of home hospice enrollees being discharged to long-term care facilities rather than common factors, such as limited financial support and resources. 


\section{Method}

The 2007 National Home and Hospice Care Survey (NHHCS) was used. NHHCS is a nationally representative sample survey of US home health and hospice agencies. The survey was conducted between August 2007 and February 2008 through in-person interviews with the agency and directors and their designated staff, and no patients or families were interviewed. Within the NHHCS, patients and discharge data were retrieved. In this subset, both home health and home hospice agencies and professionals were interviewed. Home hospice caregivers' interviews were used for this study.

\section{Variables}

\subsection{Demographic Variables}

Demographic information on the home hospice patients included, age, gender (male or female), race (American Indian or Alaska Native, Asian, Black or African American, Native Hawaiian or other Pacific Islander, White or Caucasian, Hispanic, or other), marital status (married, widowed, divorced, separated, never married, living with partner). Patient's socioeconomic status was measured by enrolled in Meals on Wheels.

\subsection{Living Arrangement Prior to Home Hospice Discharge}

Patients' living arrangement was captured, including living alone, with family members (spouse/significant other, parent, child), with non-family members, with family and non-family members.

\subsection{Level of Assistance Needed}

Patients' level of physical function and need assistance were measured by the total number of activities of daily living by family and by staff (bathing, dressing, toileting, transporting, walking, feeding).

\subsection{Reason for Discharge}

A questionnaire asking reasons for discharge (stabilized/improved, more aggressive treatment, moved, and others) and interviewers selected others provided narrative responses.

\subsection{Placements after Discharge}

A questionnaire asking where patient go after he/she was discharged from the agency were analyzed including: 1) private home or apartment; 2) residential care place; 3) skilled nursing facility; 4) hospital; 5) another hospice facility. This will alternatively help understand patients' live discharge destination rather than home.

\section{Data Analysis}

Statistical Package for the Social Science (SPSS) version 25 was used to produce 
frequency and percentages. Hierarchical logistic regression was performed to explore a possible association between nursing home discharge and remaining hospice by patients. The intention of Hierarchical logistic regression was to identify any possible moderation effect within predictor variables that commonly influence individuals' decision on hospice live discharge (e.g., gender, age, socioeconomic status). Sub-group analyses were also performed to specify interviewees' responses by discharge reason and by the revocation. To visualize narrative findings, Rstuido Version 1.6.0, WordCloud package were used. WordCloud allows visualizing most shown words within narrative responses.

The narrative response began by dividing the qualitative responses by longer-term care facility (nursing home, assisted living, residential care facilities), home, hospital, and others. A handful of narrative responses were overlapped with previous answer (Stabilized/Improved; More aggressive treatment, Moved) and questionnaire "Where did patient go after discharged from the agency," the author manually re-coded by nursing facilities or long-term care facility, to have the entire information on patients' placement after discharge. Patients transferred to different hospices were excluded from this analysis. Once re-coded, including narratives, patients' placements after discharge were divided dichotomously ( 0 = others; 1 = Long-Term Care Facility).

For the subgroup analysis, narratives were narrowed down to discharge reasons other than stabilized, hospitalization, and moved. Identified responses were recorded by 1) eligibility (patients' condition); 2) eligibility (financial); 3) hospital admission; 4) nursing facilities; 5) revoked (by caregiver); 6) revoke (by doctor); 7) revoke (by patients); 8) revoke (by family); 9) revoke (unclear); 10) unrelated emergency.

\section{Result}

Table 1 shows the demographic of interviewers for the current study. Of 9416 , 4733 were identified receiving or have received hospice care at home. Within identified home hospice patients, approximately $82.1 \%$ were deceased at discharge. Of the remaining 837 , as Table 1 shows, there were more female ( $n=$ $510,60.3 \%)$ than male patients; majority of home hospice patients were White ( $n$ $=709,83.8 \%)$ and Black or African American $(n=116,13.7)$. Living arrangements were varied. 126 patients lived alone when admitted to home hospice, 247 lived with a spouse or significant others, and 177 lived with their children. Majority of patients were either married $(n=289,35.8 \%)$ or widowed $(n=368$, $45.6 \%)$.

After discharge from home hospice, the majority of patients remained in their own residency (37.5\%), about 25 percent of live discharged patients were admitted to the hospital, and about $30 \%$ of patients transferred to the nursing facilities $(n=248)$. Prior to the live discharge, the majority of patients required assistance with at least four Activities in Daily Lives by family (29.1\%) and by staff (26.5\%), and about 70 percent of patients and family had helped with patients ADLs. 
Table 1. Demographic information for sample $(N=846)^{1}$.

\begin{tabular}{|c|c|c|c|c|c|}
\hline & & $M$ & Range & $n$ & (\%) \\
\hline \multicolumn{2}{|c|}{ Age } & 77.82 & 97 & & \\
\hline \multirow{2}{*}{ Gender } & Male & & & 336 & $39.7 \%$ \\
\hline & Female & & & 510 & $60.3 \%$ \\
\hline \multirow{3}{*}{ Race } & White & & & 665 & $80.3 \%$ \\
\hline & Black or African American & & & 115 & $13.9 \%$ \\
\hline & Hispanic/Latino/Other & & & 48 & 5.8 \\
\hline \multirow{2}{*}{ Insurance $^{2}$} & Medicare & & & 734 & $87.1 \%$ \\
\hline & Medicaid & & & 261 & $31.2 \%$ \\
\hline \multirow{3}{*}{ Living Arrangement } & Live Alone & & & 57 & $37.7 \%$ \\
\hline & Spouse/Significant Others & & & 227 & $37.5 \%$ \\
\hline & With Child & & & 177 & $26.9 \%$ \\
\hline \multirow{5}{*}{ Resources } & Home Maker & & & 205 & $24.4 \%$ \\
\hline & Assistance with ADLs & & & 576 & $68.5 \%$ \\
\hline & Continuing Care & & & 11 & $1.3 \%$ \\
\hline & Volunteers & & & 280 & $33.3 \%$ \\
\hline & Wheels on Meals & & & 25 & $3.0 \%$ \\
\hline
\end{tabular}

${ }^{1}$ Valid percentages are reported. ${ }^{2}$ Counted dual-eligible.

As expected, more than 80 percent of home hospice/discharge patients were Medicare beneficiaries, Medicaid (7\%) and only 4 percent of patients held private insurance. Only 25 patients were receiving Meals on Wheels (3\%). As for access to external resources, 205 patients had homemaker (24.4\%), volunteer (33.3\%), and only 11 patients received continuing care program (1.3\%).

\subsection{Multiple Regressions on Live Discharge to Long-Term Care Facility}

To further specify any factors that may encounter patients and families to decide on live discharge to long-term care facilities, hieratical logistic regression was performed to identify the effect of level of assistance needed and access to external services with common covariates (e.g., age, gender, income, living arrangement). The order of included variables are the total number of ADLs provided by family (Dress, Bath, Transfer, Walk, Feeding) and staff (Dress, Bath, Transfer, Walking, Feeding), and patients access to external services (Homemaker services, Assistance with ADLs, Volunteers, Continuous home care).

As Table 2 shows, the priori logistic regression revealed, the odds of patients discharged to long-term care facilities were higher when patients lives(d) with spouse or significant others $(\mathrm{OR}=4.90,95 \% \mathrm{CI}, 2.64$ to 8.97; $p<0.01)$ and with lives(d) with children (OR $=5.37,95 \% \mathrm{CI}, 2.72$ to $10.61 ; p<0.01)$. Patients receives homemaker services were more likely to be transferred to the long-term care after live discharge ( $\mathrm{OR}=1.97,95 \% \mathrm{CI}, 1.30$ to $3.00 ; p<0.01$ ), but the odds of 
discharged to long-term care facilities were lower if receiving assistance with ADLs (OR $=0.45,95 \% \mathrm{CI}, 0.31$ to $0.67 ; p<0.01)$ and receiving volunteer services $(\mathrm{OR}=0.63,95 \% \mathrm{CI}, 0.44$ to $0.90 ; p<0.01)$. Related to receiving external services for assistance with patients ADLs, patients require more assistance in completing dressing, bathing, transferring, walking, and feeding by a family member had a significantly higher likelihood of discharge to nursing facilities $(\mathrm{OR}=1.30$, 95\% CI, 1.08 to $1.56 ; p<0.01$ ), though no significant impact on patients discharge to long-term care facilities when staff provides assistance.

The result of Hierarchical Regression is shown here (refers to Table 3). The fit indices indicated good fit overall when included all variables $\left(\chi^{2}=7.51, d f=8, p\right.$ $=0.48, R^{2}=0.21$ ). While gender, living arrangement and socioeconomic status were controlled, patients receiving home care, continuing care, volunteer services, and assistance with ADLs became mediated. The odds of being discharged to long-term facilities remained higher for those patients lives(d) with spouse or significant others ( $\mathrm{OR}=3.69,95 \% \mathrm{CI}, 2.04$ to $6.67 ; p<0.01$ ) and lives(d) with children $(\mathrm{OR}=5.13,95 \% \mathrm{CI}, 2.66$ to $9.87 ; p<0.01)$.

Table 2. Priori Logistic Regression.

\begin{tabular}{cc}
\hline & Discharge to Long-Term Facilities \\
\hline Lives(d) Alone & $1.73(0.94-3.16)$ \\
Lives(d) Spouse/Significant Others & $4.90^{*}(2.67-8.97)$ \\
Lives(d) Children & $1.44(0.41-5.00)$ \\
ADLs Needs by Family & $1.16(0.54-2.46)$ \\
ADLs Needs by Staff & $0.76(0.41-1.41)$ \\
Homemaker Services & $0.31(0.07-1.40)$ \\
Assistance with ADLs & $1.44^{*}(0.91-2.30)$ \\
Volunteers & $0.90^{*}(0.58-1.39)$ \\
Continuous Homecare & $0.92^{*}(0.36-2.35)$ \\
Meals on Wheels & $0.74(0.41-1.31)$ \\
\hline
\end{tabular}

Note: ${ }^{*} p \leq 0.05$.

Table 3. Hierarchical regression.

\begin{tabular}{cc}
\hline & Discharge to Long-Term Facilities \\
\hline Lives(d) Alone & $1.68(0.91,3.92)$ \\
Lives(d) Spouse/Significant Others & $7.14^{\star}(3.39-15.03)$ \\
Lives(d) Children & $8.52^{\star}(3.88-18.73)$ \\
Meals on Wheels & $1.68(0.43,6.55)$ \\
ADLs Needs by Family & $1.25(0.96,1.64)$ \\
ADLs Needs by Staff & $0.98(0.80,1.21)$ \\
Homemaker Services & $1.12(0.62,2.02)$ \\
Assistance with ADLs & $1.39(0.61,3.15)$ \\
Volunteers & $0.73(0.41,1.28)$ \\
Continuous Homecare & $2.73(0.33,22.40)$ \\
\hline
\end{tabular}

Note: ${ }^{*} p \leq 0.05$. 
There were meaningful correlations were shown (refers to Table 4), while patients lives(d) with spouse or significant others were negatively correlated with utilizing homemaker services $(r=-0.07, p<0.01)$ and assistance with ADLs $(r=$ $-0.12, p<0.01)$, whereas lives $(\mathrm{d})$ with children were positively correlated with receiving homemaker services $(r=0.10, p<0.01)$ and assistances with ADLs $(r=$ $0.13, p<0.01)$

\subsection{Subgroup Analysis by Discharge Reasons}

Discharge reasons were, including patients being stabilized or improved $(30.2 \%)$, aggressive treatment (31.8\%), moved (e.g., geographically, 13.5\%) and others. Within patients who were discharged for other reasons $(n=207), 136$ reported revoke the care by either patient $(n=21,10.1 \%)$ or family member $(n=30$, $14.5 \%)$ or unidentified who made decision $(n=32,15.5)$.

As we see on Figure 1, nursing home admission was the most common reason for discharge from home hospice $(n=31,15 \%)$. A handful of patients were discharged due to financial reasons $(n=15,7.2 \%)$, and unrelated emergency and hospitalization (e.g., fell, fracture) was also a common factor for home hospice patients to be discharged. Importantly, those patients admitted to the hospital for other reasons than primary diagnosis ended up discharge to and remained at the nursing home $(n=2)$.

Table 4. Correlations of living arrangements and use of insurance, external services for home hospice care.

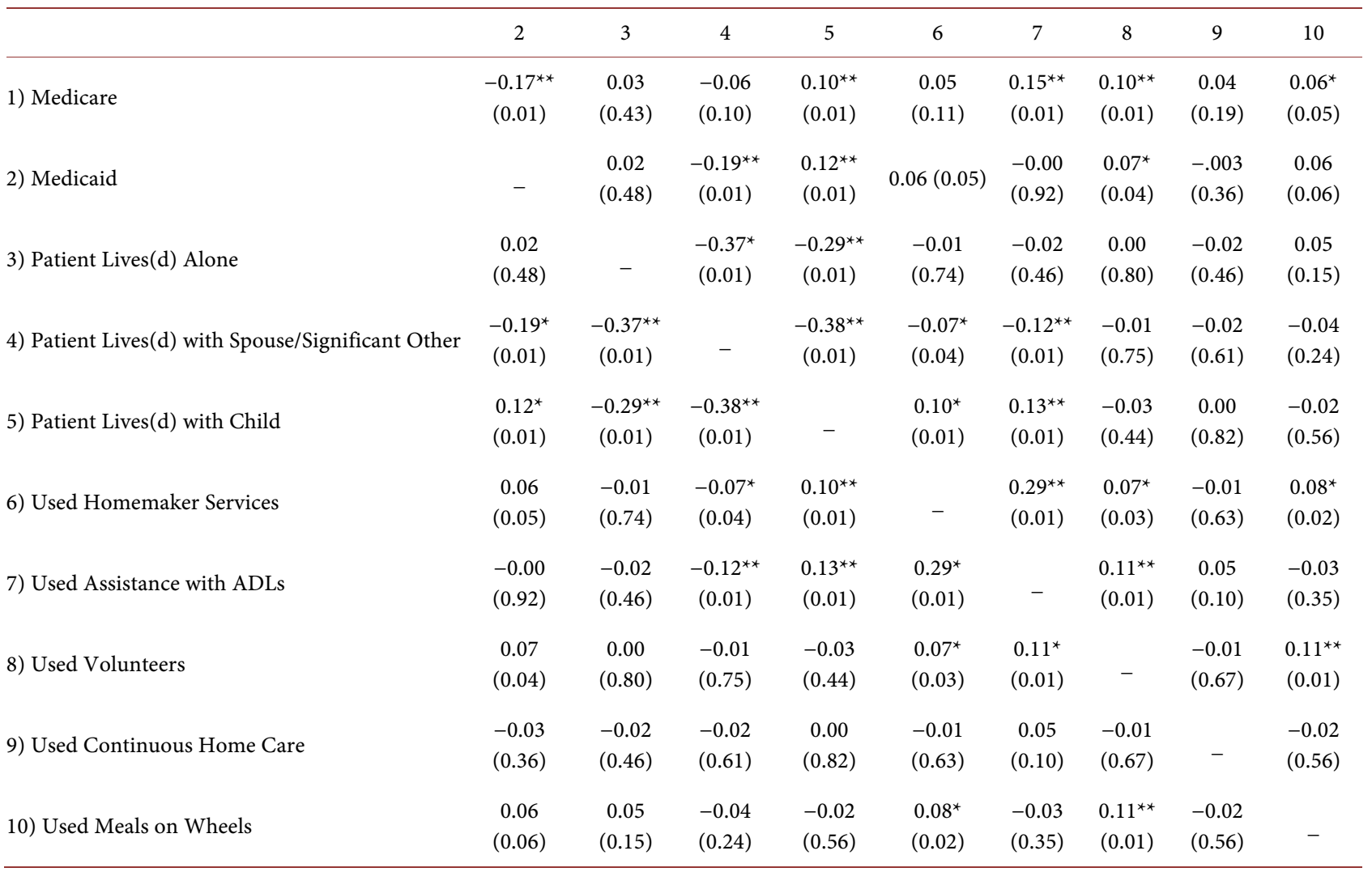

Note: ${ }^{\star} p \leq 0.05 ;{ }^{* *} p \leq 0.01$; Note: $p$ value is reported in parentheses. 


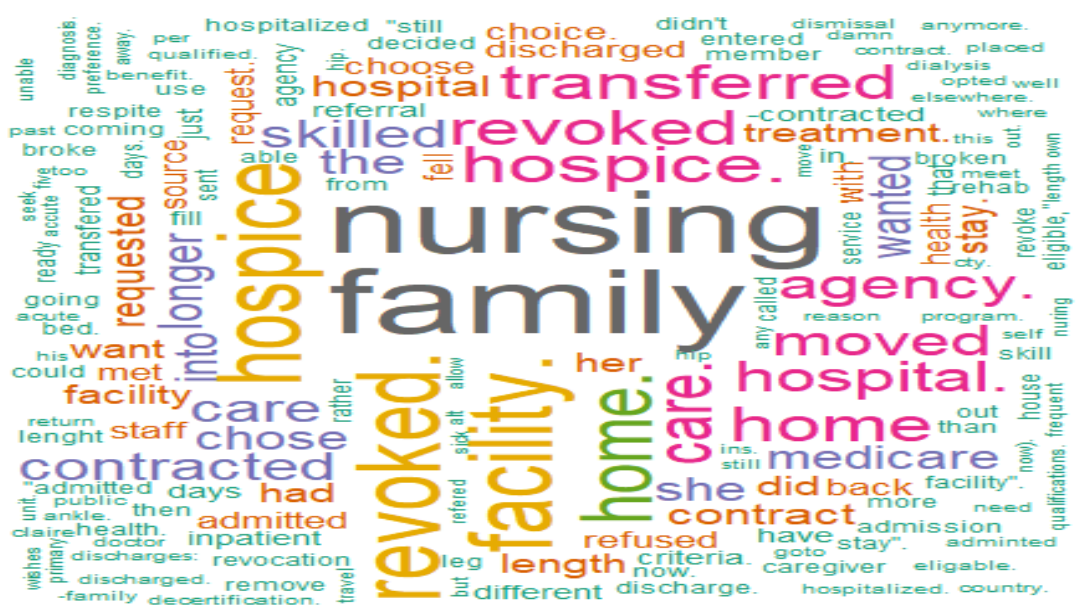

Figure 1. WordCloud.

Within patients revoked the home hospice care, more than 60 percent of patients were holding Medicare as a primary payer $(n=106)$; no significant association with the number of ADLs patient needs help from agency staff, number of visits received for nursing services, physicians' visits, volunteer visits and social service visits. It is important to note that of 207 patients, only 37 patients and families utilize volunteer services, and other nursing and physicians' visits were remaining low. While there is no significant relationship in ADLs and patients' reasons for discharge, there were slightly more patients $(n=15)$ required four or more ADLs were needed by agency staff who transferred to the nursing facilities.

\section{Discussion}

Hospice care is now available in any setting, including nursing facilities, assisted living, inpatient hospitals, or hospice [10] [25]. There is no empirical research that suggests home hospice is better than the others but considering common preferences of dying place-home [2] and home hospice might be optimal choices for many patients and families. Consequently, most hospice patients are yet to receive hospice care at their own residency [25] though the number of hospice patients in long-term care settings has increased over time [26]. The current study was not to discuss the problems of receiving hospice care other than patients' own residency. Instead, it is to discuss the reasons for patients being discharged to long-term care while they were on home hospice care.

It is not uncommon that home hospice patients are likely to rely on family support than home care routines given by agencies [27]. Most family caregivers assist in simple ADLs and perform medical and nursing tasks, including wound care, monitoring patients, and handling specialized medical equipment [28]. In the current study, patients requiring more assistance in completing common ADLs (i.e., bathing, dressing, transferring, walking, feeding) were likely to be discharged to long-term care.

Both Medicaid and Medicare and most hospice agencies provide unreimbursed care for those without coverage, including volunteers [25] [29]. The 
home hospice agencies included in the current study all have routine care at home, including nurses, home health aides, and social services designees. Perhaps, these services may not sufficiently reduce the burden on family caregivers [18] [30].

Other possibilities would be family caregivers may not utilize available resources enough. Previously suggested, mid-to older-aged spouses tend to act as primary caregivers as an obligation and less likely to utilize extra help than their children [29] [31]. The current study showed spousal caregivers were less likely to use those resources, compared to child caregivers. There was a smaller number of homecare and volunteer services were used when the spouse or significant others where the primary caregivers for the patients. Spousal caregivers may feel obligated to provide care for the patients themselves, thereby not accepting extra resources. This is a problematic as patients requiring more assistance increases a live discharge, spousal caregivers are less likely to utilize help in order to maintain well-being for both patients and the family member. Also, spousal caregivers are more common than child caregiver.

Within narrative responses, the most common reasons for discharge from home hospice were to be transferred to nursing facilities. Observable differences were identified in between living arrangements. Hospice patients who lived with the family were likely to end up discharging to the nursing home (50\%). Assumedly, this pattern suggests that despite the support and resources for those home hospice patients, it is still difficult for families to provide all necessary care for their loved ones until one's death and likely to seek external support, nursing facilities.

Previous research has indicated that patients to be remained under home hospice care heavily rely on family caregivers [14]. A burden of family caregivers is a well-known concern in a home hospice setting [27], and despite the support from agencies and volunteers, certain family caregivers are not accessing those available resources is the problem. Characteristics and reasons for the family not accessing extra help from agencies or volunteers need to be explored further.

\section{Limitations}

The current study was first to specify reasons for live discharge from home hospice and examine the possible relationship between individuals' financial assets and related physical conditions and insurance policies. However, this study concerns several limitations.

First, this study is a non-experimental, observational study that is not possibly associated with hypothetically impact families' decisions on live discharge and transfer to long-term care facilities. Further within narrative responses, there were no significant associations or correlations were found between patients' needing ADLs by staff, insurance policy (e.g., Medicare vs. Medicaid vs. private), and living arrangements (e.g., living with family or alone) by discharged to be enrolled in the nursing facilities. However, these non-significant findings could 
be meaningful. Previously, income and insurance policy played an important factor for patients and families to the nursing home due to limited resources (e.g., lack of resources). This current study suggests that volunteer and social services personnel were available as part of home hospice services, but spousal caregivers did not utilize these resources. Further, although performing ADLs does not indicate that the family has less to provide for the patients, it is noteworthy to look at the number of ADLs that individual patients and families did not significantly influence in deciding to revoke the care and transfer to nursing facilities.

The second limitation is that the data used in this current study is outdated. The interview was collected between the year 2007-2008. However, home hospice benefit has not been modified significantly since early 2000 [1] [10] and similar studies explored home hospice patients' live discharge using data collected between 2000 to 2013 [32]. This current study was the first to specify the reasons to be discharged (i.e., narrative responses) and understand the pattern of accessing extra assistance by spousal and child. Yet, newer home hospice data needs to be studied to examine the most up-to-date patterns with updated benefits that are available to patients and families.

\section{Conclusion}

Home hospice can benefit both families and patients at the end of the stage. Home hospice care will allow patients to receive care at home, where they feel most comfortable and can die at the most preferred location, home. Simultaneously, the trend suggests many individuals are now accepting hospice care and palliative care at home than in the past. However, spousal caregivers are often obligated to become primary caregivers, thereby less likely to utilize services available for them, thereby overwhelmed and transferred to nursing facilities. Reducing family caregivers' obligations is essential.

\section{Conflicts of Interest}

The author declares no conflicts of interest regarding the publication of this paper.

\section{References}

[1] Centers for Medicare and Medicaid Services: Hospice. http://www.cms.gov/Medicare/Medicare-Fee-for-Service-Payment/Hospice/index.h $\underline{\mathrm{tml}}$

[2] Arnold, E., Finucane, A.M. and Oxenham, D. (2015) Preferred Place of Death for Patients Referred to a Specialist Palliative Care Service. BMJ Supportive and Palliative Care, 5, 294-296. https://doi.org/10.1136/bmjspcare-2012-000338

[3] Wilson, D.M., Cohen, J., Deliens, L., Hewitt, J.A. and Houttekier, D. (2013) The Preferred Place of Last Days: Results of a Representative Population-Based Public Survey. Journal of Palliative Medicine, 16, 502-508. https://doi.org/10.1089/jpm.2012.0262 
[4] Seaman, J.B., Bear, T.M., Documet, P.I., Sereika, S.M. and Albert, S.M. (2016) Hospice and Family Involvement with End-of-Life Care: Results from a Population-Based Survey. American Journal of Hospice and Palliative Medicine, 33, 130-135. https://doi.org/10.1177/1049909114550392

[5] Candy, B., Holman, A., Leurent, B., Davis, S. and Jones, L. (2011) Hospice Care Delivered at Home, in Nursing Homes and in Dedicated Hospice Facilities: A Systematic Review of Quantitative and Qualitative Evidence. International Journal of Nursing Studies, 48, 121-133. https://doi.org/10.1016/j.ijnurstu.2010.08.003

[6] Medicare Payment Advisory Commission (2004) Hospice Care in Medicare: Recent Trends and a Review of the Issues. In: Report to Congress. New Approaches in Medicare, 139-152.

[7] Medicine Payment Advisory Commission (2006) Report to the Congress: Increasing the value of Medicare.

[8] Beccaro, M., Costantini, M., Rossi, P.G., Miccinesi, G., Grimaldi, M. and Bruzzi, P. (2006) Actual and Preferred Place of Death of Cancer Patients. Results from the Italian Survey of the Dying of Cancer (ISDOC). Journal of Epidemiology and Community Health, 60, 412-416. https://doi.org/10.1136/jech.2005.043646

[9] Brazil, K., Howell, D., Bedard, M., Krueger, P. and Heidebrecht, C. (2005) Preferences for Place of Care and Place of Death among Informal Caregivers of the Terminally Ill. Palliative Medicine, 19, 492-499.

https://doi.org/10.1191/0269216305pm1050oa

[10] Prsic, E., Plotzke, M., Christian, T.J., Gozalo, P. and Teno, J.M. (2016) A National Study of Live Hospice Discharges between 2000 and 2012. Journal of Palliative Medicine, 19, 987-990. https://doi.org/10.1089/jpm.2015.0383

[11] Joan, M.T., Michael, P., Pedro, G. and Vincent, M. (2014) A National Study of Live Discharges from Hospice. Journal of Palliative Medicine, 17, 1121-1127. https://doi.org/10.1089/jpm.2013.0595

[12] Kutner, J.S., Meyer, S.A., Beaty, B.L., Kassner, C.T., Nowels, D.E. and Beehler, C. (2004) Outcomes and Characteristics of Patients Discharged Alive from Hospice. Journal of the American Geriatrics Society, 52, 1337-1342. https://doi.org/10.1111/j.1532-5415.2004.52365.x

[13] Joan, M.T., Jason, B., Michael, P., Pedro, L.G., Thomas, C., Susan, C.M., Cindy, W. and Vincent, M. (2015) Characteristics of Hospice Programs with Problematic Live Discharges. Journal of Pain and Symptom Management, 50, 548-552. https://doi.org/10.1016/j.jpainsymman.2015.05.001

[14] Rebeka, W.C. (2015) Being Discharged from Hospice Alive: The Lived Experience of Patients and Families. Journal of Palliative Medicine, 18, 495-499. https://doi.org/10.1089/jpm.2014.0228

[15] Johnson, K.S., Elbert-Avila, K., Kuchibhatla, M. and Tulsky, J.A. (2012) Characteristics and Outcomes of Hospice Enrollees with Dementia Discharged Alive. Journal of the American Geriatrics Society, 60, 1638-1644. https://doi.org/10.1111/j.1532-5415.2012.04117.x

[16] Taylor, D.H., Steinhauser, K., Tulsky, J.A., Rattliff, J. and Van Houtven, C.H. (2008) Characterizing Hospice Discharge Patterns in a Nationally Representative Sample of the Elderly, 1993-2000. American Journal of Hospice and Palliative Medicine, 25, 9-15. https://doi.org/10.1177/1049909107310136

[17] Barclay, J.S., Kuchibhatla, M., Tulsky, J.A. and Johnson, K.S. (2013) Association of Hospice Patients' Income and Care Level with Place of Death. JAMA Internal Medicine, 173, 450-456. https://doi.org/10.1001/jamainternmed.2013.2773 
[18] Hassankhani, H., Rahmani, A., Best, A., Taleghani, F., Sanaat, Z. and Dehghannezhad, J. (2020) Barriers to Home-Based Palliative Care in People with Cancer: A Qualitative Study of the Perspective of Caregivers. Nursing Open, 7, 1260-1268. https://doi.org/10.1002/nop2.503

[19] Froggatt, K.A. (2001) Palliative Care and Nursing Homes: Where Next? Palliative Medicine, 15, 42-48. https://doi.org/10.1191/026921601671222652

[20] Maccabee, J. (1994) The Effect of Transfer from a Palliative Care Unit to Nursing Homes-Are Patients' and Relatives' Needs Met? Palliative Medicine, 8, 211-214. https://doi.org/10.1177/026921639400800304

[21] Enes, S.P.D., Lucas, C.F., Aberdein, N. and Lucioni, J. (2004) Discharging Patients from Hospice to Nursing Home: A Retrospective Case Note Review. International Journal of Palliative Nursing, 10, 124-130. https://doi.org/10.12968/ijpn.2004.10.3.12468

[22] Wallston, K.A., Burger, C., Ann, S.R. and Baugher, R.J. (1988) Comparing the Quality of Death for Hospice and Non-Hospice Cancer Patients. Medical Care, 26, 177-182. https://doi.org/10.1097/00005650-198802000-00008

[23] Shepperd, S., Wee, B. and Straus, S.E. (2011) Hospital at Home: Home-Based End of Life Care. Cochrane Database of Systematic Reviews, No. 7, Article No. CD009231. https://doi.org/10.1002/14651858.CD009231

[24] NHPCO Facts and Figures (2018) Hospice Care in America, Alexandria, VA: National Hospice and Palliative Care Organization, September 2017.

[25] Harris-Kojetin, L., Sengupta, M., Lendon, J.P., Rome, V., Valverde, R. and Caffrey, C. (2019) Long-Term Care Providers and Services Users in the United States, 2015-2016. National Center for Health Statistics, Vital and Health Statistics, Series 3, No. 43.

[26] Albright, D.L., Washington, K., Parker-Oliver, D., Lewis, A., Kruse, R.L. and Demiris, G. (2016) The Social Convoy for Family Caregivers over the Course of Hospice. Journal of Pain and Symptom Management, 51, 213-219. https://doi.org/10.1016/j.jpainsymman.2015.09.005

[27] Tjia, J., Ellington, L., Clayton, M.F., Lemay, C. and Reblin, M. (2015) Managing Medications during Home Hospice Cancer Care: The Needs of Family Caregivers. Journal of Pain and Symptom Management, 50, 630-641. https://doi.org/10.1016/j.jpainsymman.2015.06.005

[28] Lima, J.C., Allen, S.M., Goldscheider, F. and Intrator, O. (2008) Spousal Caregiving in Late Midlife versus Older Ages: Implications of Work and Family Obligations. The Journals of Gerontology Series B: Psychological Sciences and Social Sciences, 63, S229-S238. https://doi.org/10.1093/geronb/63.4.S229

[29] Reblin, M., Donaldson, G., Ellington, L., Mooney, K., Caserta, M. and Lund, D. (2016) Spouse Cancer Caregivers' Burden and Distress at Entry to Home Hospice: The Role of Relationship Quality. Journal of Social and Personal Relationships, 33, 666-686. https://doi.org/10.1177/0265407515588220

[30] Jeong, A., Shin, D., Park, J.H. and Park, K. (2020) Attributes of Caregivers' Quality of Life: A Perspective Comparison between Spousal and Non-Spousal Caregivers of Older Patients with Cancer. Journal of Geriatric Oncology, 11, 82-87. https://doi.org/10.1016/j.jgo.2019.05.020

[31] Luth, E.A., Russell, D.J., Xu, J.C., Lauder, B., Ryvicker, M.B., Dignam, R.R., Baughn, R., Bowles, K.H. and Prigerson, H.G. (2021) Survival in Hospice Patients with Dementia: The Effect of Home Hospice and Nurse Visits. Journal of the American Geriatrics Society, 1-10. https://doi.org/10.1111/jgs.17066

[32] Russell, D., Baik, D., Jordan, L., Dooley, F., Hummel, S.L., Prigerson, H.G., Bowles, 
K.H. and Creber, R.M. (2019) Factors Associated with Live Discharge of Heart Failure Patients from Hospice: A Multimethod Study. JACC: Heart Failure, 7, 550-557. https://doi.org/10.1016/j.jchf.2019.01.010 